\title{
PRSEUS Development for the Hybrid Wing Body Aircraft
}

\author{
Alex Velicki ${ }^{1}$ \\ The Boeing Company, Huntington Beach, California 92647-2099 \\ Dawn Jegley $^{2}$ \\ NASA Langley Research Center, Hampton, Virginia 23681-2199
}

\begin{abstract}
NASA has created the Environmentally Responsible Aviation (ERA) Project to explore and document the feasibility, benefits and technical risk of advanced vehicle configurations and enabling technologies that will reduce the impact of aviation on the environment. A critical aspect of this pursuit is the development of a lighter, more robust airframe that will enable the introduction of unconventional aircraft configurations that have higher lift to drag ratios, reduced drag, and lower community noise. The primary structural concept being developed for the Hybrid Wing Body aircraft design under the ERA project in the Airframe Technology element is the PRSEUS concept. This paper describes how researchers at NASA and Boeing are working together to develop fundamental PRSEUS technologies that could someday be implemented on a transport size HWB airplane design.
\end{abstract}

\section{Nomenclature}

$\begin{array}{ll}L / D & =\text { lift divided by drag } \\ N x & =\text { component of running load acting in the streamwise direction } \\ N y & =\text { component of running load acting in the spanwise direction } \\ \mathrm{Nz} & =\text { component of resultant internal pressure load }\end{array}$

\section{Introduction}

$\mathrm{N}$ ASA has created the Environmentally Responsible Aviation (ERA) Project to explore and document the feasibility, benefits and technical risk of advanced vehicle configurations and enabling technologies that will reduce the impact of aviation on the environment. A critical aspect of this pursuit is the development of a lighter, more robust airframe that will enable the introduction of unconventional aircraft configurations that have higher lift to drag ratios, reduced drag, and lower community noise. A Hybrid Wing Body (HWB) aircraft is one configuration that will address all of these goals. The HWB is the first vehicle considered under the NASA Environmentally Responsible Aviation Project. Creating a non-circular pressure cabin that is not only lightweight but also economical to produce, is the primary challenge constraining the implementation of a large lifting-body design like HWB. Many smaller flying wing configurations are in the air today but a larger payload volume is needed for the HWB to achieve commercial viability. The lack of a usable payload volume continues to be one of the most daunting challenges remaining for more widespread application of HWB structure. To begin addressing this fundamental constraint, researchers at NASA and The Boeing Company are developing a new structural concept called the Pultruded Rod Stitched Efficient Unitized Structure (PRSEUS) that was specifically created to address the unique structural and manufacturing challenges inherent in the HWB design space. The progress along this development arc of structural concept evolution and subscale testing forms the basis of the work described in this paper. The test specimens described herein were fabricated, or are currently being fabricated, by The Boeing Company, while the structural analyses and testing tasks are divided between the two organizations.

\section{HWB Structural Concept Development}

One constant since the beginning of pressurized flight has been the circular fuselage - effective because it maintains a tension-biased loading state without the introduction of secondary bending stresses. By contrast, the

\footnotetext{
${ }^{1}$ Principal Design Engineer, The Boeing Company, Advanced Structures R\&D, AIAA Associate Fellow.

${ }^{2}$ Senior Aerospace Engineer, NASA-LaRC, Structural Mechanics and Concepts Branch, AIAA Associate Fellow.
} 
starting premise for the HWB design is that by achieving a higher L/D through vehicle shaping, the corresponding weight increase resulting from the use of a non-circular pressure cabin can be offset, ultimately resulting in a better performing airplane design. Whether such a premise is valid or not remains to be confirmed, but what is commonly understood is that even before such a problem can be addressed, a much higher performing structural solution is needed to operate within this demanding design space.

\section{A. Noncircular Considerations}

Although significantly lighter than conventional aluminum structures, even the most highly efficient composite primary structures used on today's state-of-the-art aircraft would not be adequate to overcome the weight and cost penalties introduced by the highly contoured airframe of the HWB. Particularly, in the pressure cabin regions that are primarily driven by out-of-plane loading considerations, a traditional layered material system would require thousands of mechanical attachments to suppress delaminations and to join structural elements, ultimately leading to fastener pull-through problems in the thin gauge skins. The other argument against a conventional composite solution is the high manufacturing costs associated with the highly contoured airframe. Not only will complex outer moldline tooling be needed, but all of the interior stringers and frame members would require individual toolsets and ultimately individual parts - which would adversely affect affordability. The essential characteristics of a more capable HWB structural solution is one that operates effectively in out-of-plane loading scenarios, while simultaneously meeting the demanding producibility requirements inherent in building a highly contoured airframe.

\section{B. Maneuver Loading Considerations}

In addition to the secondary bending stresses experienced during pressurization, another key difference in the HWB shell is the unique bi-axial loading pattern that occurs during maneuver loading conditions. For the HWB, the load magnitudes are more nearly equal in each in-plane direction ( $\mathrm{Nx}$ and $\mathrm{Ny}$ ) than what is typically found on conventional tube-and-wing fuselage arrangements where the cantilevered fuselage is more highly loaded in the $\mathrm{Nx}$ direction, along the stringer, than in the Ny direction, along the frame. This single difference has a profound effect on the structural concept selection because it dictates that the optimum panel geometry should have continuous load paths in both directions ( $\mathrm{Nx}$ and $\mathrm{Ny}$ ), in addition to efficiently transmitting internal pressure loads (Nz) for the nearflat panel geometry (Fig. 1). Additionally, for a conventional skin-stringer-frame built-up panel, the frame shear clip member is typically discontinuous to allow the stringer to pass through uninterrupted in the primary longitudinal loading direction. If such an arrangement were used for the HWB, the frame member (attached by a discontinuous shear clip to the skin) would be less effective in bending and axial loading than a continuous frame design that is attached directly to the skin, ultimately resulting in a non-competitive solution.

To overcome these problems, an improved fuselage panel should be designed as a bi-directionally stiffened panel, where the wing bending loads are carried by the frame members and the fuselage bending loads are carried by the stringers. Additionally, the panel design should also include continuous loads paths in both directions, stringer and frame laminates that are highly tailored, thin skins designed to operate well into the post-buckled design regime, and crack-stopping features designed to minimize damage propagation. Capturing such improvements is necessary to overcome the inherent weight penalties of the non-circular pressure cabin.

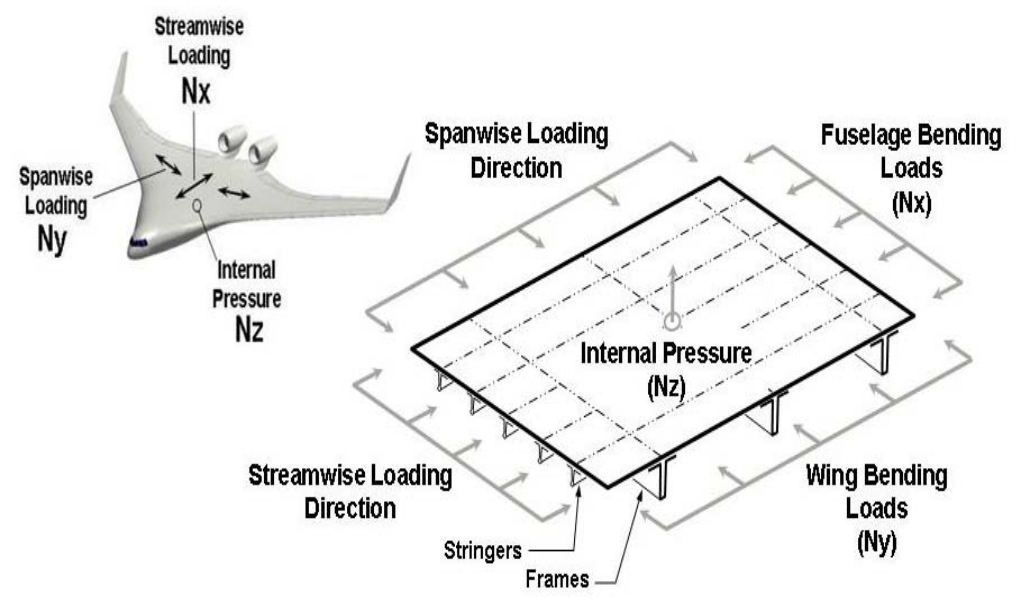

Figure 1. Combined loading on HWB pressure cabin.

\section{Structural Concept Attributes}

The PRSEUS design and fabrication approach incorporates these design features, resulting in a highly effective structural concept. It is a conscious progression away from conventional laminated and bonded methods of assembly, and has evolved to become a one-piece cocured panel design with seamless transitions and damage-arrest interfaces. The highly integrated nature of the PRSEUS stiffened panel design is enabled by the use of 
through-thickness stitching, which ultimately leads to unprecedented levels of fiber tailoring and structural optimization potential.

The dry warp-knit fabric, pre-cured rods, and foam-core materials are assembled and then stitched together to create the PRSEUS structural geometry for the HWB fuselage loading (Fig. 2). Load path continuity at the stringer-frame intersection is maintained in both directions by passing the rod-stringer through a small keyhole in the frame web. The 0-degree fiber dominated pultruded rod increases local strength/stability of the stringer section while simultaneously shifting the neutral axis away from the skin to further enhance the overall panel bending capability. Frame elements are placed directly on the IML skin surface and are designed to take advantage of carbon fiber tailoring by placing bending and shear-conducive lay-ups where they are most effective. The stitching is used to suppress out-of-plane failure modes. Suppressing these modes enables a higher degree of tailoring than would be possible using conventional laminated materials. The resulting bi-directionally stiffened panel design is ideal for the HWB pressure cabin because it is not only highly efficient in all three loading directions, but also stitched to react pull-off loading and increase panel survivability.

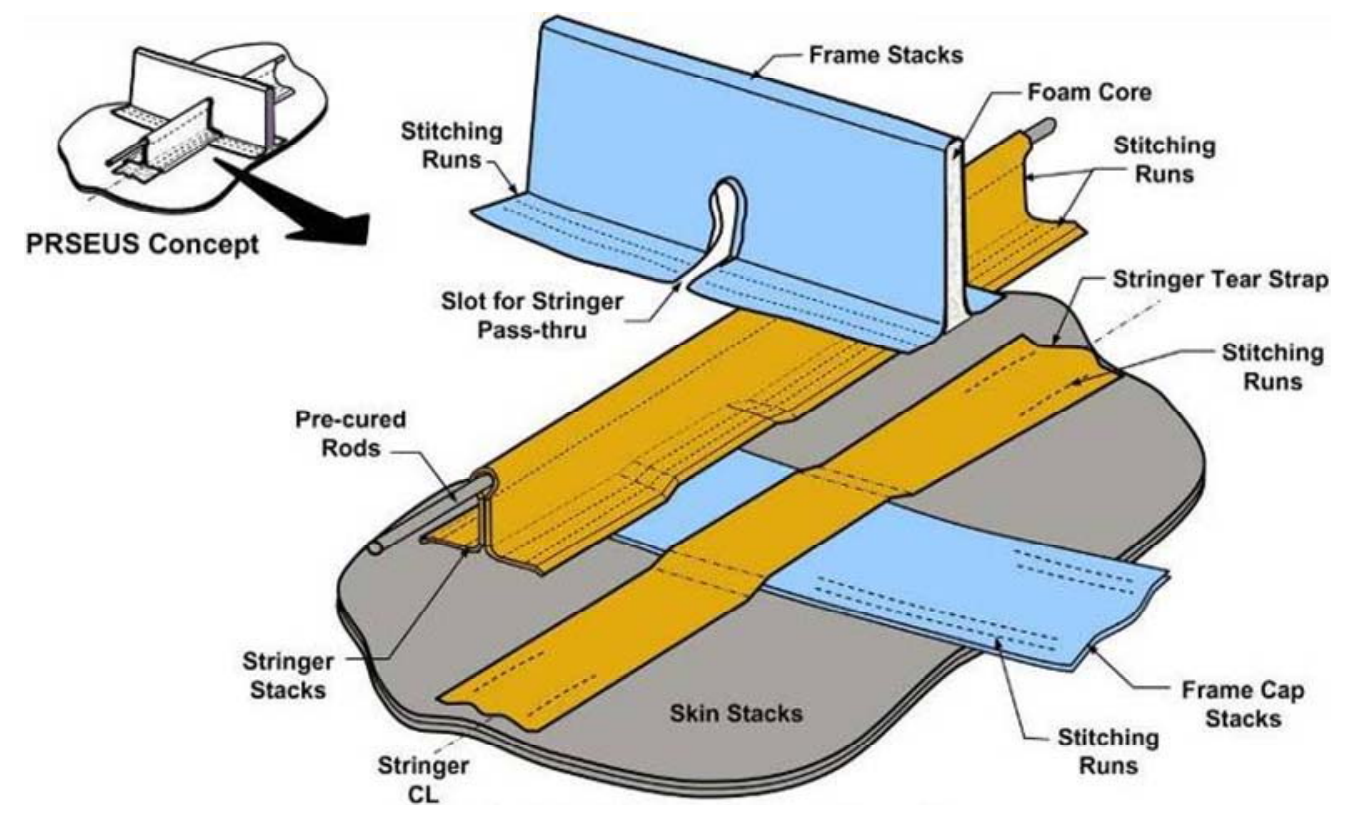

Figure 2. Exploded view of Pultruded Rod Stitched Efficient Unitized Structure (PRSEUS) concept.

While such attributes are essential for improving performance, the producibility goals cannot be ignored. The fundamental breakthrough is the self-supporting stitched preform assembly that can be fabricated without exacting tolerances, and then accurately net molded in a single oven-cure operation using high-precision outer moldline tooling (Fig. 3). Since all of the materials in the stitched assembly are dry, there are no out-time or autoclave limitations as in prepreg systems, which can restrict the size of an assembly because it must be cured within a limited processing envelope. Resin infusion is accomplished using a soft tooled fabrication method where the bagging film conforms to the inner moldline surface of the preform geometry and seals against a rigid OML tool, thus eliminating costly internal tooling that would normally be required to form net-molded details. The manufacture of multiple PRSEUS panels (References 1-3) proved that the essential feature of this concept - the self-supporting preform that eliminates interior mold tooling - was feasible for the near-flat geometry of the HWB airframe.

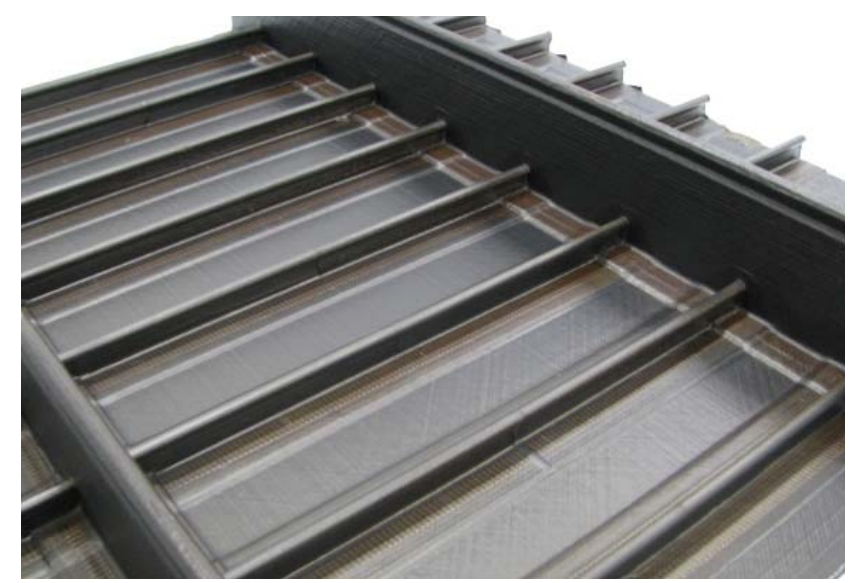

Figure 3. Interior surface of cured PRSEUS panel. 


\section{Structural Feasibility Testing}

A limited test program was established to measure key PRSEUS attributes under representative HWB pressure cabin loading conditions (Fig. 4). Specimen sizing and load levels were derived from a series of FEM-based trade studies that calculated panel geometries and internal loading distributions for a baseline set of airplane requirements. Initial element-level testing was performed to assess the basic structural response of the PRSEUS frame and stringer elements under static and fatigue loading scenarios. Once those results verified the structural integrity of the panel architecture, a more complex set of subcomponent tests was performed to begin addressing the flat panel response under fundamental HWB fuselage loading conditions. Three large subcomponent test specimens (tension, compression, and pressure) were designed and tested to measure the panel response in these three critical loading directions - as well as generate failure load levels that could be used to calibrate the panel sizing results and airframe weights generated in the trade studies. The test results for these subcomponent tests are summarized in the following sections of this paper. To begin addressing the challenging three-dimensional aspects of the flat-sided design, a cube shaped test article was constructed of PRSEUS panels and then joined together to create a pressure-tight unit that could be internally pressurized to simulate the $2 \mathrm{P}$ static loading condition for the fuselage. Additional small-scale tests have also been planned and completed but are not discussed herein.

The results from all of the panel and cube tests were then used to design a final representative proof-of-concept test article that would be capable of simulating the unique HWB combined-loads condition. To accomplish this, a

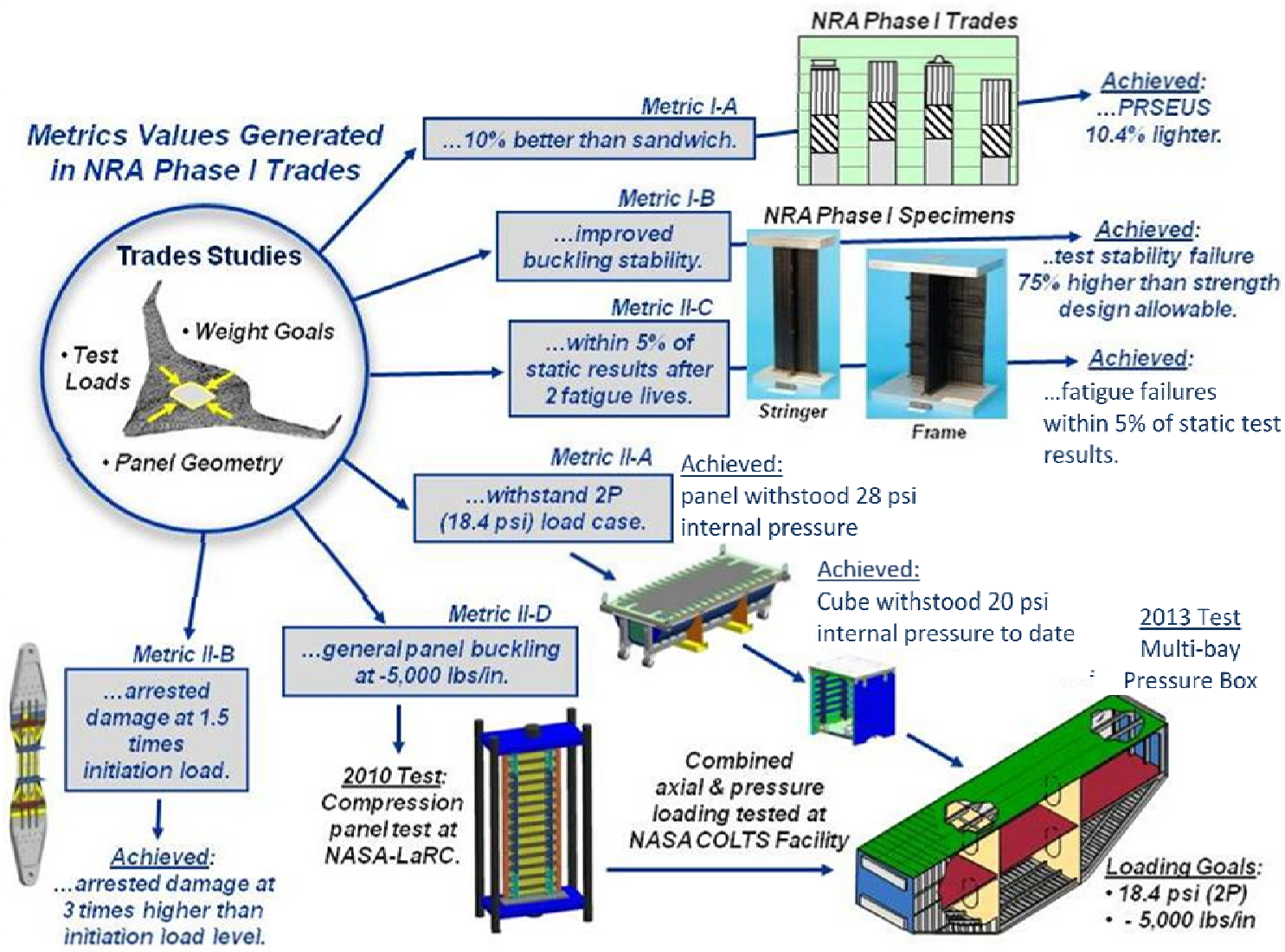

Figure 4. Pressure cabin feasibility testing approach leading to multi-bay test article.

large-scale, multi-bay test article was necessary to accurately replicate the internal pressure plus maneuver loading condition that occurs during the 2.5-g flight maneuver condition. Such a test article is currently under development and will be tested in the future to validate the initial premise of whether the PRSEUS structural concept is capable of meeting the stringent airframe performance and producibility goals necessary to successfully enable a next-generation, lifting-body architecture like that of the HWB aircraft.

\section{A. Pressure Panel Test Article}


A flat PRESEUS test panel with two frames and 15 stringers was constructed and mounted on an open-sided steel pressure vessel so that internal pressures $(\mathrm{Nz})$ could be applied to the interior surface. The panel was 108 inches long by 48 inches wide, with 20 -inch frame spacing, 6 -inch stringer spacing, and a nominal skin gauge of 0.052 inches. A photograph of the panel interior surface is shown in Figure 5 prior to being attached to the test fixture (Fig. 6). A bonded external doubler plate was installed around the panel perimeter to provide load continuity where the frames and stringers terminate at the test fixture land. The ends of the frame members were also mechanically fastened to the test fixture at the ends to simulate the fixed boundary condition found on the airplane. A detailed description of the panel, finite element analysis, and experimentation task is presented in References 4 and 5.

The pristine panel was subjected to the $2 \mathrm{P}$ loading condition (18.4 psi), while strains and displacements were recorded. Displacements determined analytically and measured experimentally using a video image correlation system are compared in Figure 7 at 18.4 psi (only the central region of the panel is shown). Good agreement is seen between the predicted and experimental behavior, and no damage was apparent at this load level.

After the 2P loading was removed, a $20 \mathrm{ft}-\mathrm{lb}$ low-speed impact damage was inflicted upon a central stringer using a spring-loaded impactor with a 1-inch diameter ball tip. Damage to the surface paint could be seen but no evidence of fiber damage was observed. The panel was then loaded again to $18.4 \mathrm{psi}$ of internal pressure. Once again no evidence of failure could be determined. The pressure was slowly increased to 28.4 psi when an audible failure was heard and a discontinuity was measured in the load-strain and load-displacement behaviors near the center of the panel. However, the panel continued to hold pressure, indicating that the panel skin was fully intact. Loading was then increased to the instrumentation limits of $30 \mathrm{psi}$ before the test was stopped. A photograph of the damaged central stringer is shown in Figure 8. Fiber damage appears to have originated at the outer most region of the wrap stack that encapsulates the rod and then progressed into the web, but did not progress further into the flange and skin areas. Damage appears to have been arrested at the stitch line in the web fillet closest to the skin. No fiber damage was apparent anywhere else, although ultrasonic scans indicated the presence of delamination in several stringers between the flange and skin. Delamination only occurred at the edge of the flange away from the web, indicating that the stitching through the flange and skin prevented further delamination growth across the flange. Since both the pristine and impact-damaged panel supported the required $2 \mathrm{P}$ load case, the panel exceeded the design requirement. Since the damage occurred at approximately 3P of internal pressure and was then arrested prior to reaching the skin, the robust pull-off, as well as the damage-arrest capability of stitching was demonstrated.

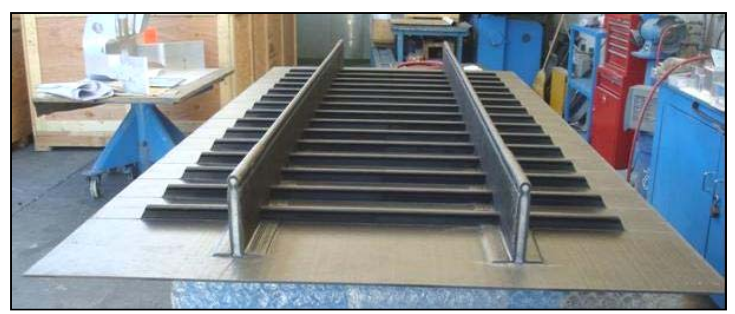

Figure 5. Pressure panel interior side.

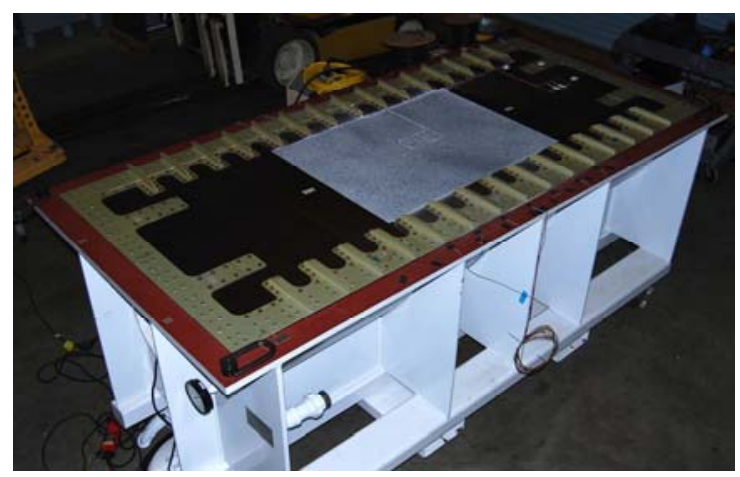

Figure 6. Pressure panel in its fixture.

\section{Expcriment}

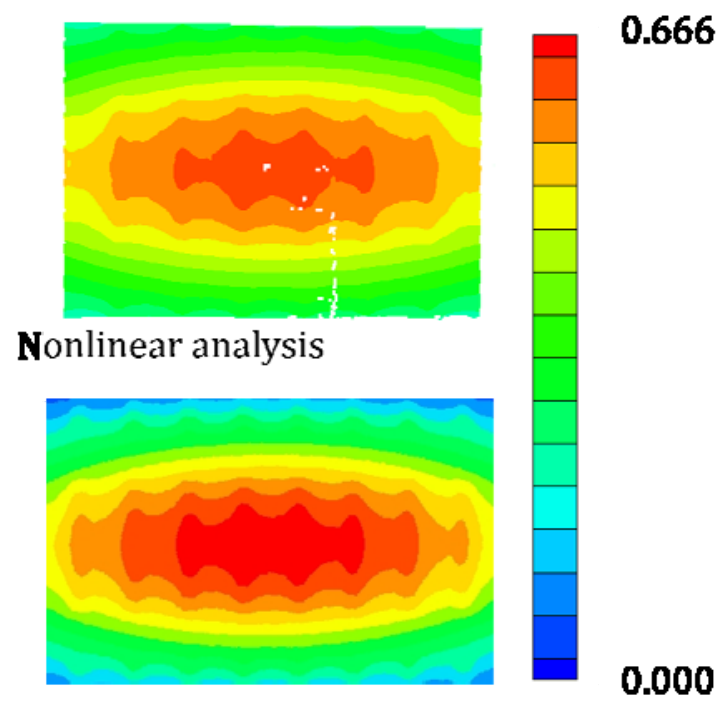

Figure 7. Panel displacement in inches (2P loading).

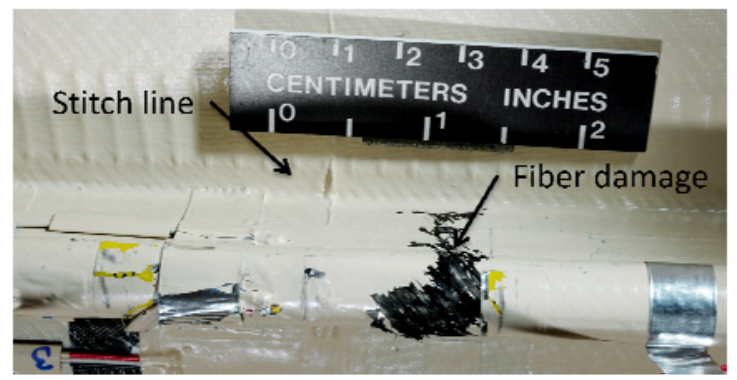

Figure 8. Center stringer failure at $28.4 \mathrm{psi}$. 


\section{B. Compression Panel Test Article}

A flat PRSEUS panel nominally identical to the pressure panel was fabricated and prepared for compression loading along the frame direction ( $\mathrm{Ny}$ ) to simulate the spanwise bending condition in the fuselage crown. Potted aluminum end plates and side restraints were added for load introduction and to stabilize the panel edges (Fig. 9). A detailed description of the panel, finite element analysis, and experimentation task is presented in References 4 and 6.

The pristine panel was subjected to unidirectional compressive loading to failure, while strains and displacements were recorded. Local skin bucking between the stiffeners was predicted to occur at a load of 59,000 lbs but actually occurred at 23,000 lbs, presumably due to initial geometric imperfections in the panel. However, as anticipated, the panel continued to support loads greater than the local bucking load and finally failed at a load of approximately $147,000 \mathrm{lbs}$. Strains were determined analytically and then measured experimentally using a video image correlation system. The peak strain distribution is shown plotted in Figure 10 just prior to failure. The peak strain locations in the analytical results (Fig. 11) correspond well to peak strains in the experimental results (Fig. 10). Both methods indicated the presence of high strains at the panel edges and in the frame webs at the stringer-frame intersections above Stringer 10 where the failure occurred. Displacement measurements on the frames recorded little deformation for loads less than 120,000 lbs - with no indication of failure until the global failure occurred at $147,000 \mathrm{lbs}$. This result indicates that the panel withstood approximately six times the local buckling load prior to failure, or approximately 73,000 lbs/frame, and ultimately exceeded the allowable material strength before encountering a general panel buckling mode. The final failure runs through a keyhole in both frames, under the restraints and to the edge of the panel, seemingly connecting the locations of peak strains predicted by the FEM-based analysis, as well as those recorded by the video displacement system.

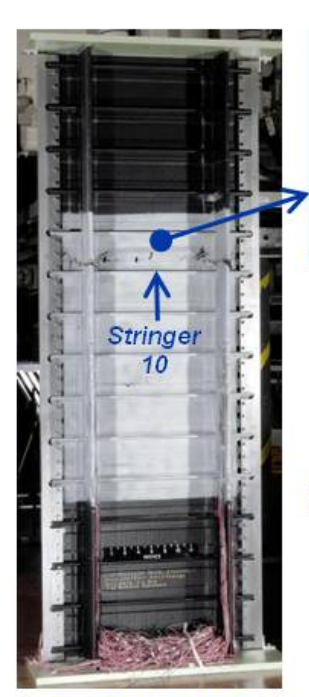

Failed Specimen
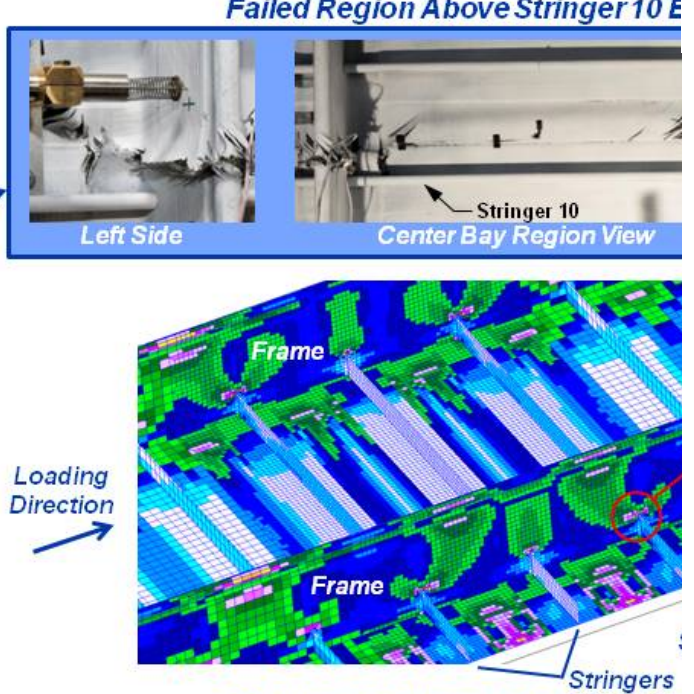

FEMStrains Plotted at Failure Loa
Failed Region Above Stringer $10 \mathrm{E}$

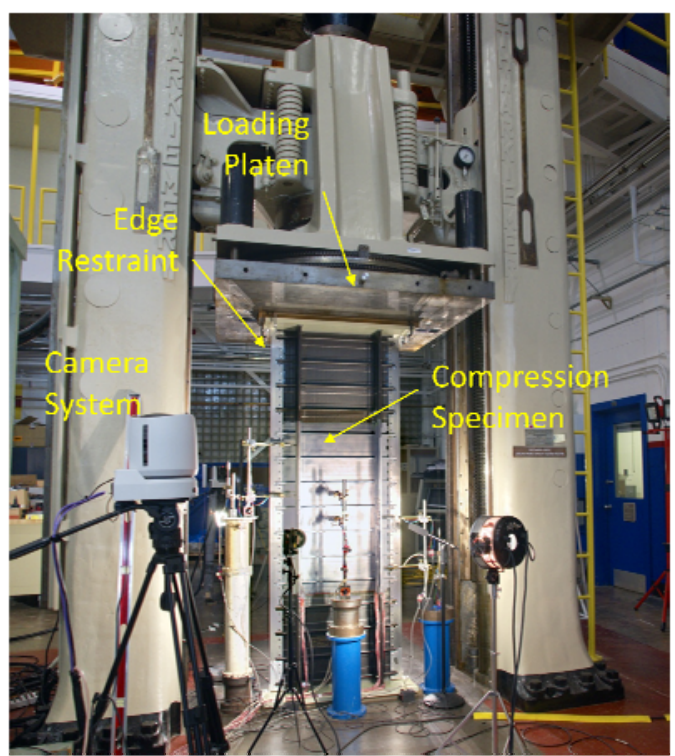

Figure 9. Compression test set-up.

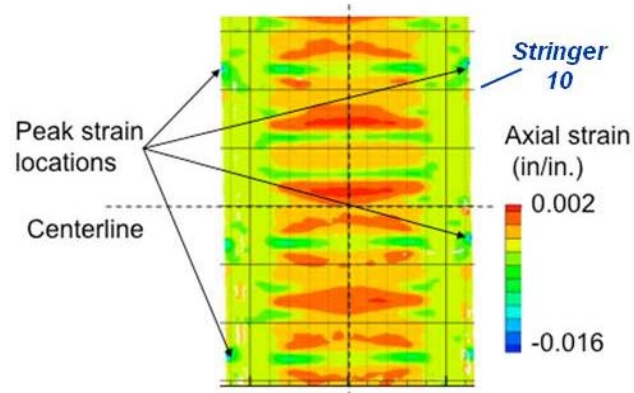

Figure 10. Measured axial strains at 147,000 lbs.

Figure 11. Post failure test panel compared with FEM strain results at 147,000 lbs. 


\section{Tension Panel Test Article}

A flat PRSEUS 3-stringer tension specimen with the same frame and stringer spacing, panel thicknesses, and laminate orientations as in the pressure and compression panels described above was fabricated to evaluate its behavior under tension loading along the stringer direction $(\mathrm{Nx})$. A conventional dog-bone specimen design using pin-loaded end fittings, bonded aluminum doublers, and increased skin gauge at the ends was used to provide uniform loading across the nominal 3-stringer test region (Fig. 12.) A detailed description of the panel, finite element analysis, and experimentation task is presented in References 4 and 7.

Since the primary purpose of this test was to demonstrate the capability of stitched structures to arrest damage and redistribute internal loading, the central stringer, including the flange and skin, was severed mid-bay to mid-bay, creating a 6-inch-long, 0.25-inch-wide notch with rounded edges. With approximately one third of the panel cross-sectional removed, only one effective skin-and-stringer combination remained on either side of the notch to carry loading through the test section.

The panel was loaded in uniaxial tension to failure and followed the expected

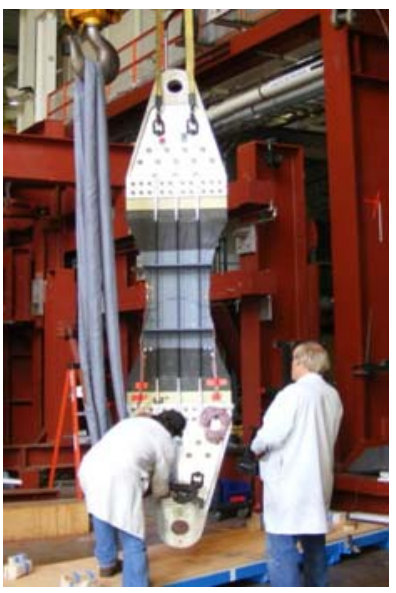

Figure 12. Test Article. response as damage sites grew before being arrested at the stitched boundaries. Although cracking was first visible at the notch edges at 46,000 lbs and continued to grow as loads were increased, the overall panel response was generally linear up to $138,000 \mathrm{lbs}$ until one side of the skin failed, causing the first load drop down to 112,000 lbs (Fig. 13). From this point, loading was resumed up to 125,000 lbs until the remaining skin material failed, causing a second smaller load drop. Again, loading was resumed before the specimen finally failed at $146,000 \mathrm{lbs}$ as the two remaining stringers sequentially failed and the rod elements broke.

The general damage pattern followed three distinct phases. Initially at $64,000 \mathrm{lbs}$, cracking was visible emanating from both sides of the notch - as splitting of the 45-degree surface plies of the warp-knit fabric (Fig. 14). Initially this damage was arrested at the edge of the stringer flange, but soon progressed under the build-up where it was stopped at the stitch row. The ability to stop damage progression with stitching was clearly visible at the higher load levels (Fig. 15) where on the outside surface of the specimen (painted white), surface cracking was observed as it crossed the trace of the flange edge before being stopped at the stitch row trace. The next distinct phase of damage progression occurred at 122,000 lbs, as it moved vertically along the stringer before finally being arrested by

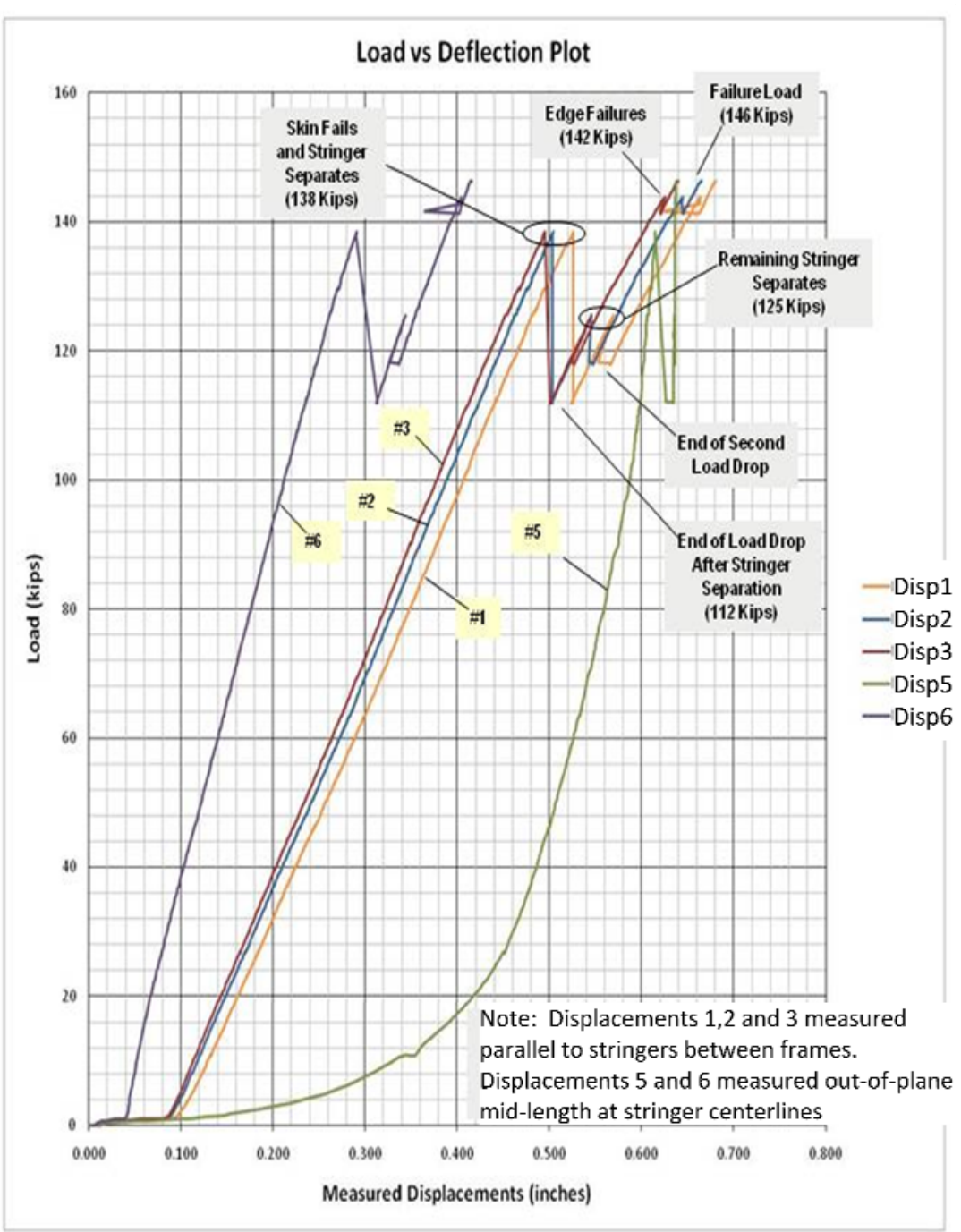

Figure 13. Tension loading versus specimen displacement plot. 

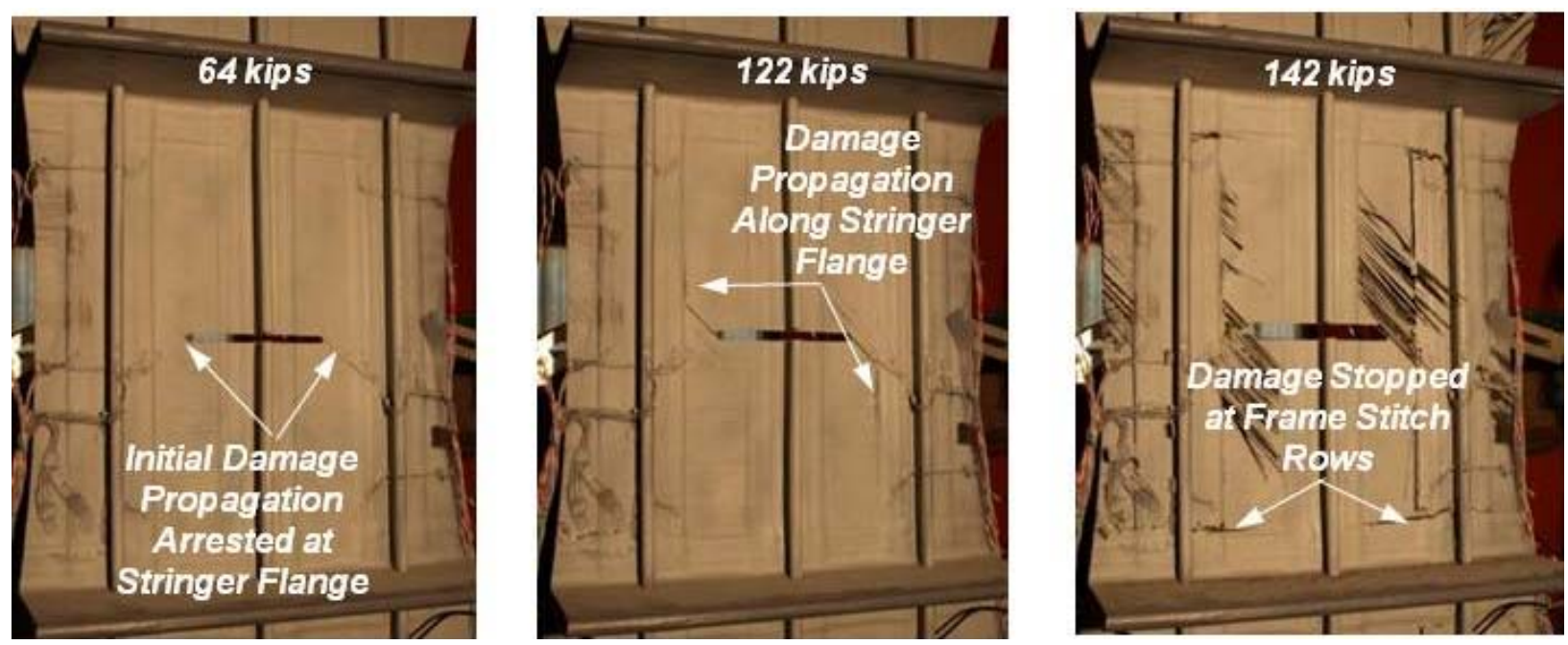

Figure 14. Principal stages of damage propagation up to final specimen failure at 146 kips.

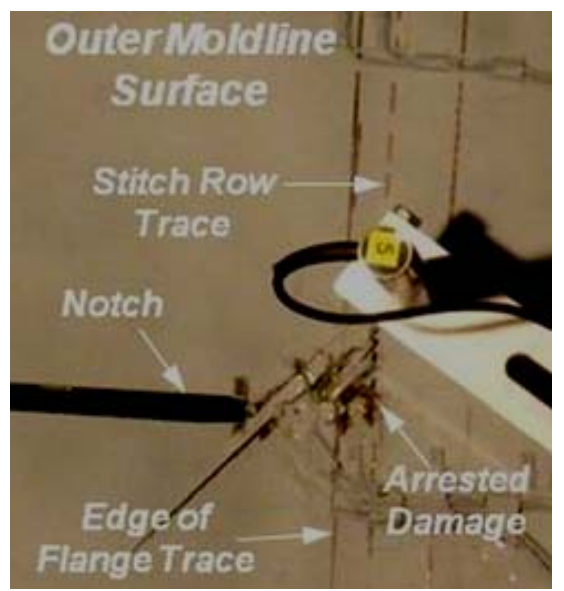

Figure 15. Damage at 130,000 lbs.

the perpendicular frame tear strap at $142,000 \mathrm{lbs}$, shortly before the final failure at 146,000 lbs.

The post-test evaluation indicated that the final failure occurred when the right side stringer rod broke, causing the left side stringer to fail below the lower frame, and then pull through the frame as the specimen became unbalanced (Fig. 16). The final failure load was about one third higher than was needed to meet the $100 \%$ design limit load requirement determined for the discrete source damage load case using the given specimen geometry and structural gauges. The widespread damage inflicted across the specimen was also indicative of the damage-arrest capability displayed at the

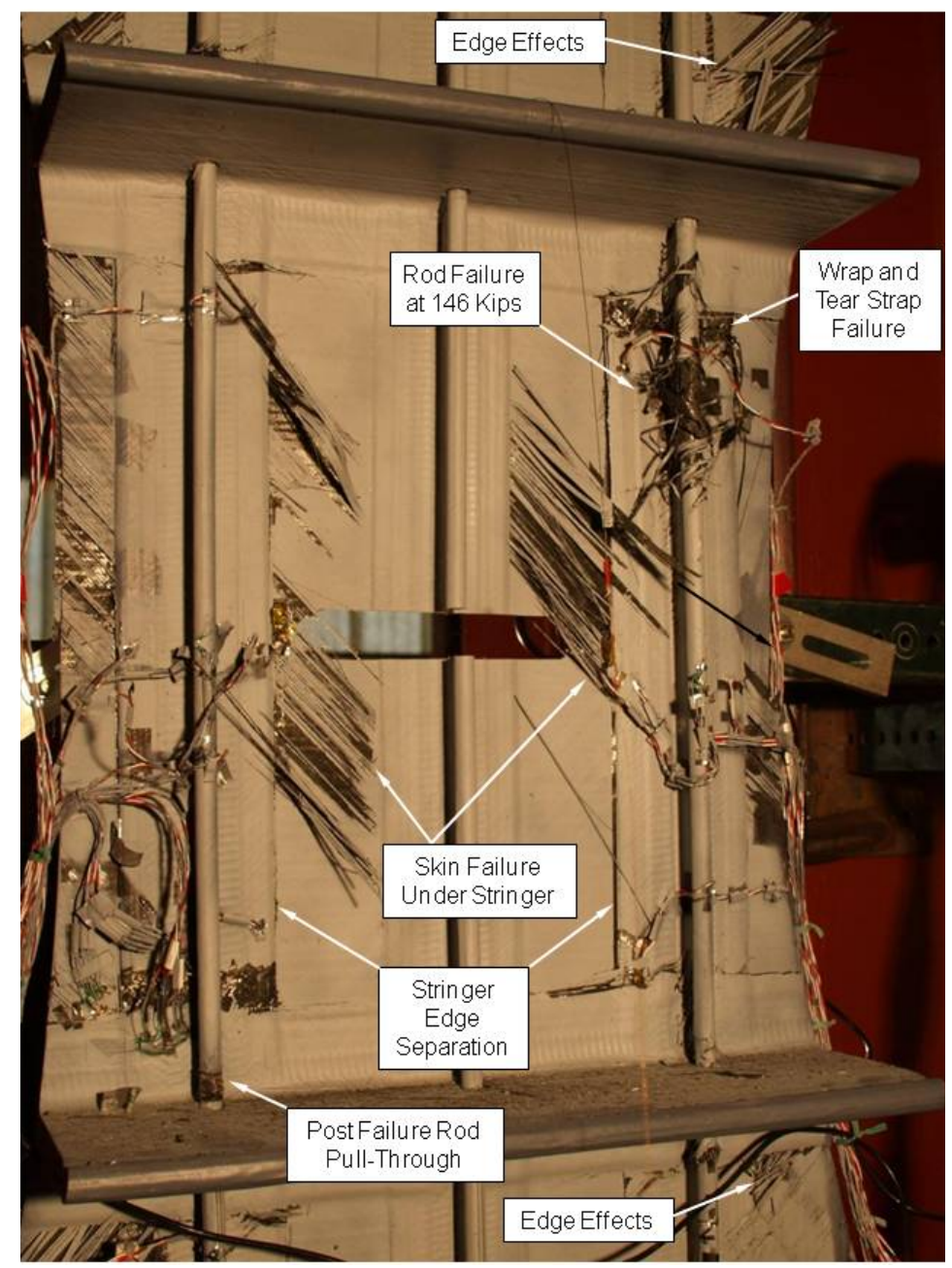

Figure 16. Failed Specimen (max load 146,000 lbs.) stitched interfaces, as delaminations were stopped and stiffening elements remained intact to permit ever increasing load levels, until the point where the rods failed leading to catastrophic failure of the entire specimen. 


\section{Cube Test Article}

The purpose of the Cube subcomponent (Fig. 17) was to cost effectively demonstrate some of the difficult structural transitions encountered in a flat-sided pressure vessel. Beyond assessing the obvious corner and side splice configurations, the difficult challenge of maintaining bending moment continuity in the frame elements as they transition around the 90-degree corners would also be encountered - for both the frame-to-frame transitions (crown panel to rib panel) and in the frame-to-stringer transitions (crown panel to bulkhead panel). Then by applying pressure greater than needed for a flight vehicle to the $4 \mathrm{x} 4 \mathrm{x} 4 \mathrm{-ft}$ test article, higher bending moments and panel strains could be developed that would ultimately be representative of a full-scale aircraft.

The specimen is constructed of 6 highly integrated panel assemblies where each panel contains stringer, frame, and edge cap features that are stitched and infused as single units before being bolted together to create the box structure (Fig. 18). Aluminum fittings and mechanical attachments are used to maintain load continuity in the corners and for the frame splices and runouts.

To validate the pressure cube design, strength and stability analyses were performed under the 2P (18.4 psi) internal pressure-loading condition. These analyses included creating a global finite element model (FEM) to simulate the pressure cube structures, and performing linear static and linear buckling analyses with the global FEM. Threedimensional solid elements were used in modeling the frame sandwich cores. Titanium fasteners were modeled by special MSC-Nastran CFAST fastener connector elements. There are total 253,575 nodes, 279,056 elements, and 2,144 fastener connector elements in the global FEM.

Maximum principal strains of 0.0065 in/in were calculated (Fig. 19) at the keyhole area on the bulkhead frame web, and a minimum principal strain of -0.0041 in/in was observed at the bulkhead frame web. The minimum margin of safety is $8 \%$ located at the bulkhead frame web at the keyhole edge where the stringer passes through. The high principal stresses are caused by frame twisting under $2 \mathrm{P}$ pressure loads. The remaining margins on the composite parts are higher than $30 \%$. Linear buckling analyses were also performed on the frames and was not found to be critical in the as-tested undamaged condition.

Since the global FEM was constructed primarily of 2dimensional plate elements, it lacked the capability for analyzing interlaminar stresses where cap members are subjected to pull-off loads and bending moments resulting in high interlaminar tension and shear stresses. In these cases, local analyses were used to show that the mid-plane of the laminate might be critical for the integral cap features. However, since the interior locations are less susceptible to damage, the use of a notched allowable in the analysis may be unwarranted. With severe impact damage present, the analysis showed that although a local mid-plane resin failure was possible at the fillet, it would be arrested immediately by the stitching without altering the load-carrying capability of the joint. The ambiguity of this result reinforced the original premise of the test, which was to begin evaluating and validating some of the more complex 3-dimensional effects that are inherent in the flat pressure cabin design, which are

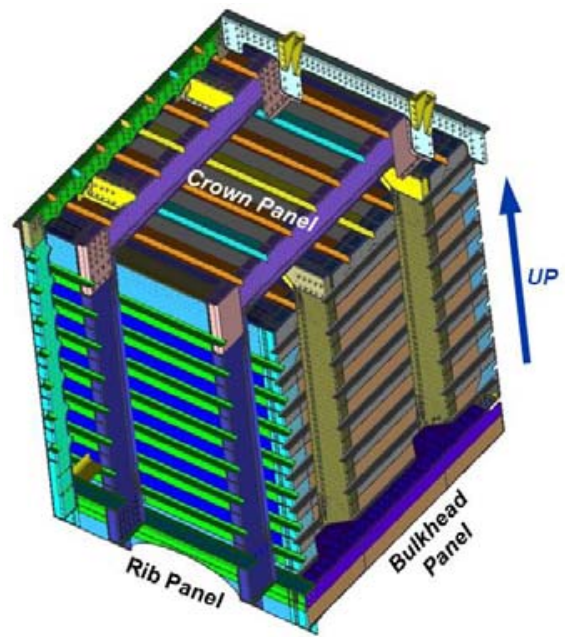

Figure 17. Interior view (panels removed).

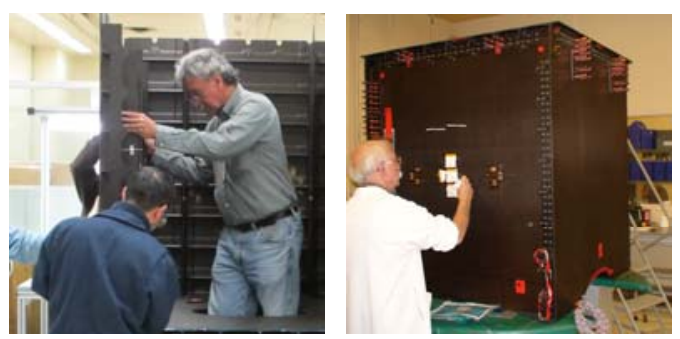

Figure 18. Determinant assembly used.

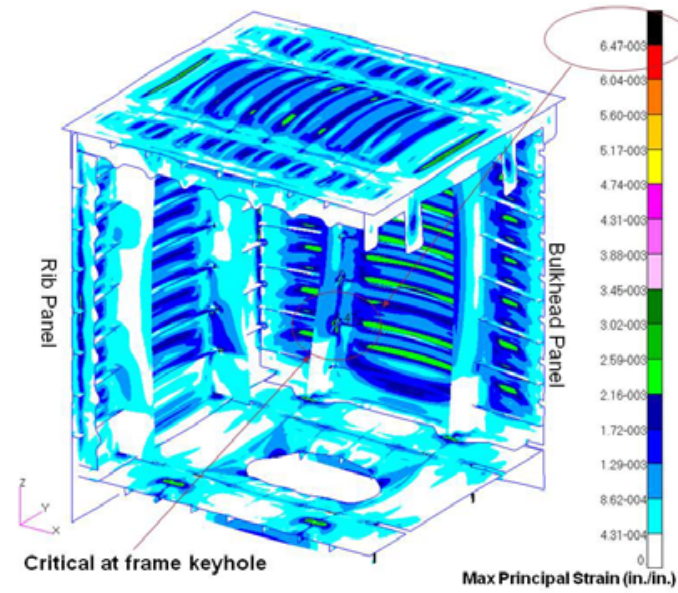

Figure 19. FEM critical strains (2P). difficult to analyze and evaluate without a comprehensive allowables and testing database. The cube test will be conducted in the Combined Loads Test System (COLTS) facility at NASA-LaRC in the fall of 2011. 


\section{E. Multi-Bay Box Test Article}

The multi-bay test article was designed to replicate the unique combined axial-plus-pressure loading condition that takes place on the upper crown panel at the wing intersection (Fig. 20). To replicate this interaction, as well as test for the $2 \mathrm{P}$ static proof load case, the specimen was designed as a closed vessel capable of maintaining $18.4 \mathrm{psi}$ (Fig. 21). Wing bending loads are introduced for the 2.5-g and -1.0-g load cases through rigid end platens that are rotated about the specimen mid plane (slightly above the floor). For the critical 2.5-g maneuver, the center bay of the crown panel reaches an average running load of $-5,000$ lbs/in across its width, which correlates to the test results of the compression panel subcomponent.

Based on the same design and manufacturing features as the cube test article, the double-deck, multi-bay box structure is built up using flat PRSEUS panels comprising integrally stitched stringer, frame, and cap features, that are then mechanically fastened to one another. The panel assemblies have nominal 24-inch frame pitch and 6-inch stringer spacing, with 0.052-inch thick skins in the center bay that gradually increase as they approach the concentrated loads imparted by the end fittings. Load continuity around the sharp corners of the individual bays is maintained using mechanically-attached aluminum fittings and intercostals.

Strength and stability analyses were performed using a global FEM created for linear static and linear buckling analyses containing 15 panels (cover, floor, two upper bulkhead, two lower bulkhead, two side rib, two side keel, lower keel, and four center rib panels), aluminum fittings and access doors, and titanium bolts. One-dimensional bar elements were used to model the pultruded rod and the wrap stack. Two-dimensional shell elements were used in modeling skins, stringer flanges and webs, T-section caps, frame webs, and aluminum fittings. One-dimensional bar elements were also used at the frame cap locations to simulate the frame cap stiffness. Titanium fasteners were modeled with special MSC Nastran CFAST fastener connector elements. There are a total of 693,045 nodes, 676,718 elements, and 18,517 fastener connector elements in the global FEM, including the load introduction platens and boundary conditions. (Fig. 22)

Five critical load cases were run: 2.5-g, 2.5-g+1P, -1.0-g, and $-1.0-\mathrm{g}+1 \mathrm{P}$ maneuver conditions, as well as the static $2 \mathrm{P}$ ground condition to size the overall test article structure. The limit load displacements for the critical 2.5-g+1P load case are shown plotted in Figure 23. Although the maximum displacements occur in the center of the outer bay pressure bulkheads, the critical region will be the center of the upper crown panel where the deflected panel must also simultaneously carry spanwise compressive loads, and is thus susceptible to general panel buckling. This is the critical nonlinear loading regime that forms the basis for the combined loads testing that will be conducted in the NASA-LaRC COLTS facility at a future date.

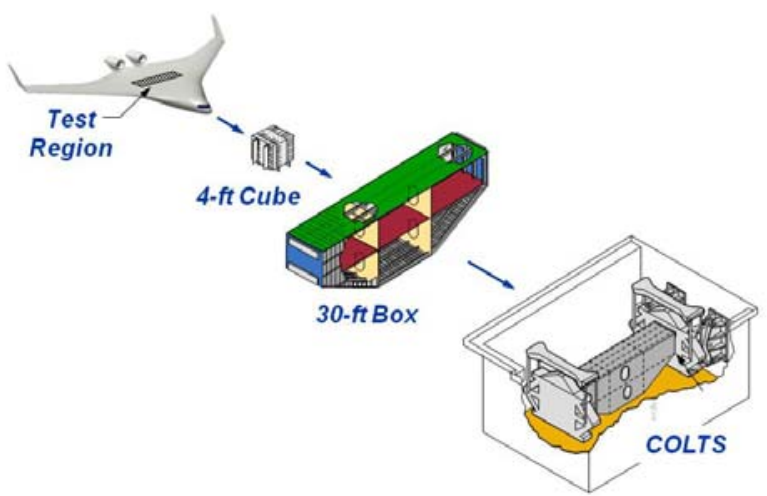

Figure 20. Specimen development approach.

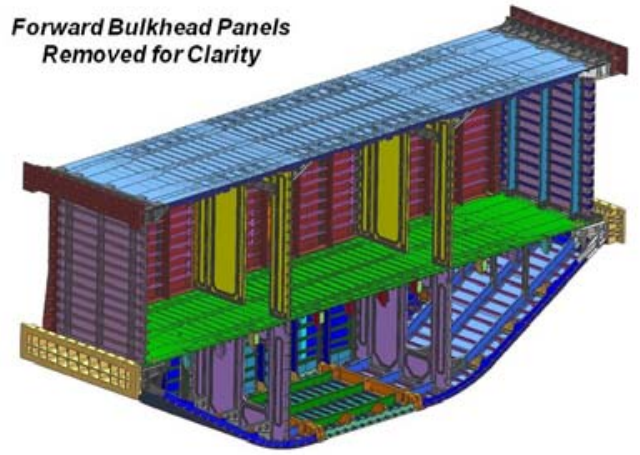

Figure 21. Multi-bay specimen design.

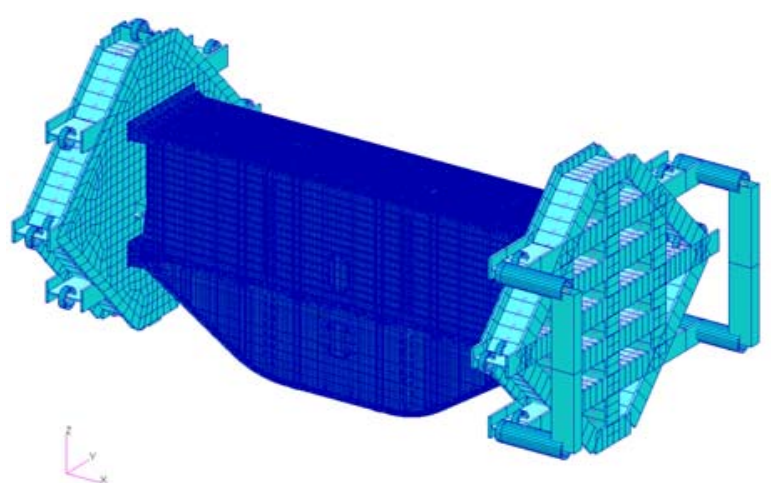

Figure 22. Multi-bay specimen FEM.

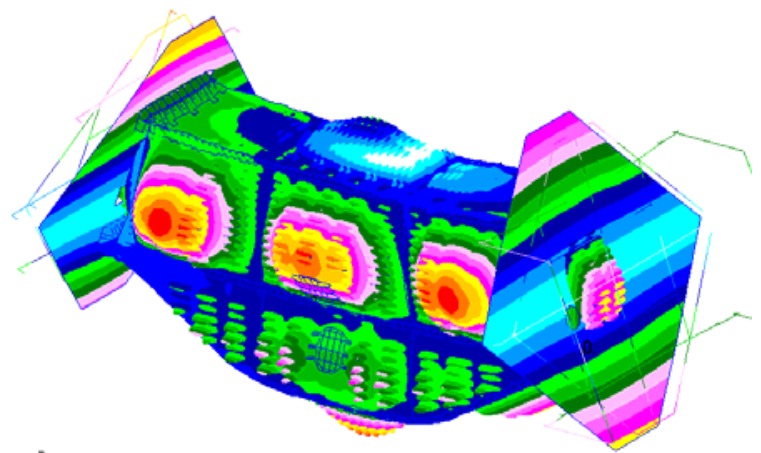

Figure 23. Displacements 2.5-g+1P (limit load). 


\section{Conclusion}

The HWB design approach represents an opportunity to move beyond incremental airplane performance improvements by radically reshaping the aircraft centerbody to achieve first order aerodynamic improvements in $\mathrm{L} / \mathrm{D}$. The success of such an approach rests squarely on the development of an advanced structural concept that is capable of offsetting the structural weight and cost penalties inherent in the non-circular centerbody design. To meet these challenges, researchers at NASA and Boeing have developed a highly engineered structural solution that moves beyond traditional composite design practices to offer a highly efficient structural solution that can be operated substantially beyond conventional no-growth design techniques and limitations. The result is a very efficient airframe structure that combines the skin, stringers, and frame elements into an integral structural solution for reacting the complex combined loading of the HWB airframe, as well as addressing the producibility challenges inherent in its compound curvature. This unique approach represents a bold vision in composite design theory and oven-cure manufacturing methods. It is a departure from conventional multi-detail laminated and bonded/bolted composite assembly practices, and is an evolution toward larger, one-piece, cocured panel designs with seamless transitions and stitched interfaces. Characterization of this innovative approach to airframe shaping and structural concept development is the primary objective of the coordinated research work being performed by NASA and Boeing researchers under the structures portion of the NASA Environmentally Responsible Aviation initiative.

\section{References}

${ }^{1}$ Hoffman, K., Air Vehicle Technology Integration Program (AVTIP), Delivery Order 0059, “Multi-role Bomber Structural Analysis,” AFRL-VA-WP-TR-2006-3067, May 2006, Final Report for 14 December 2004 - 08 May 2006.

${ }^{2}$ Velicki, A., and Thrash P.J., “Advanced Structural Concept Development Using Stitched Composites,” 49th AIAA/ASME/ASCE/AHS/ASC Structures, Structural Dynamics, and Materials Conference, paper number AIAA-2008-2329, June 2008, Schaumburg, IL.

${ }^{3}$ Velicki, A., “Damage Arresting Composites for Shaped Vehicles - Phase I Final Report”, NASA/CR-20091-215932, September 2009, Final Report for October 2007 - September 2008, contract number NNL07AA48A.

${ }^{4}$ Velicki, A., Yovanof, N., Baraja, J., Linton, K., Li, V., Hawley, A., Thrash, P., DeCoux, S., and Pickell, R., "Damage Arresting Composites for Shaped Vehicles - Phase II Final Report,” NASA/CR-2011-216880, January 2011, Final Report for October 2008 - September 2010, contract number NNL07AA48A.

${ }^{5}$ Lovejoy, A., Rouse, M., Linton, K., and Li, V., "Pressure Testing of a Minimum Gauge PRSEUS Panel," 52nd AIAA Structures Dynamics and Materials Conference, paper number AIAA-2011-1813, April 2011, Denver, CO.

${ }^{6}$ Yovanof, N., and Jegley, D., “Compressive Behavior of Frame-Stiffened Composite Panels,” 52nd AIAA Structures Dynamics and Materials Conference, paper number AIAA-2011-1913, April 2011, Denver, CO.

${ }^{7}$ Velicki, A., and Thrash, P.J., "Damage Arrest Design Approach Using Stitched Composites,” 2nd Aircraft Structural Design Conference, Tuesday 26 - Thursday 28 October 2010, No.4 Hamilton Place, London, UK. 